\title{
Studies on stereoselective separations of the "azole" antifungal drugs ketoconazole and itraconazole using HPLC and SFC on silica-based polysaccharides
}

\author{
A. Thienpont ${ }^{1}, \mathrm{~J} \mathrm{Gal}^{2}$, C. Aeschlimann ${ }^{2}$ and G. Félix ${ }^{1}$ \\ ${ }^{1}$ ENSCPB, Avenue Pey-Berland, BP 108, 33402 Talence, France \\ ${ }^{2}$ Division of Clinical Pharmacology and Toxicology, University of Colorado School of Medicine, Denver, CO 80262, USA
}

The resolution of ketoconazole and itraconazole enantiomers has been studied in HPLC and SFC on chiral stationary phases based upon substituted polysaccharides with different groups such as 3,5-dimethylphenylcarbamates and (R)-phenylethylcarbamate. The separations have been studied particularly in SFC (influence of pressure, temperature, as well as type and percentage of organic modifier). This study shows the advantages of SFC over HPLC for the enantiomeric separation of these antifungal agents.

Keywords: SFC, HPLC, CSPS, enantioselective separations, azoles

\section{Introduction}

The incidence of serious fungal infections has increased dramatically in recent decades. This increase is mainly due to the advent of HIV and to the increased use of cancer chemotherapy and of immunosuppressive therapies in organ transplantation [1,2]. The treatment of fungal diseases involves several classes of antifungal agents, among which the imidazole- or triazole-based drugs (referred to collectively as the "azoles") constitute a large and important group [3]. The azoles are, at present, the only antifungal agents with good oral bioavailability and activity against a broad spectrum of fungal pathogens. However, the azoles are not free from adverse side effects. For example, some azoles, e.g. ketoconazole (KETO) and itraconazole (ITRA), are potent inhibitors of cytochrome P450 (CYP) 3A4, an important drug-metabolizing enzyme, and such inhibition of CYP can cause severe and sometimes even fatal drug-drug interactions $[4,5]$. Thus, there is clearly a need for safer azole antifungal agents.

KETO and ITRA are chiral drugs, and each is used clinically as a stereoisomeric mixture. KETO is the racemic (i.e. $1: 1)$ mixture of the enantiomers (non-superposable mirrorimage forms) of cis configuration, as shown in figure 1. Cis

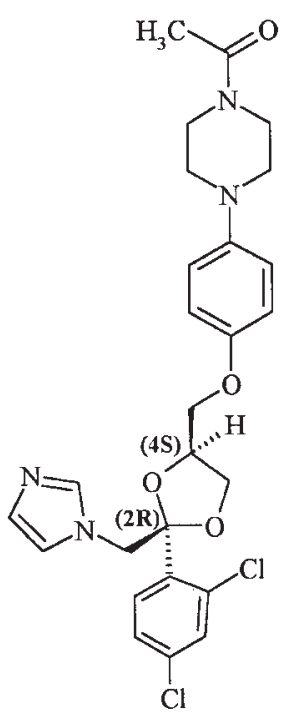

$(+)-(2 R, 4 S)$

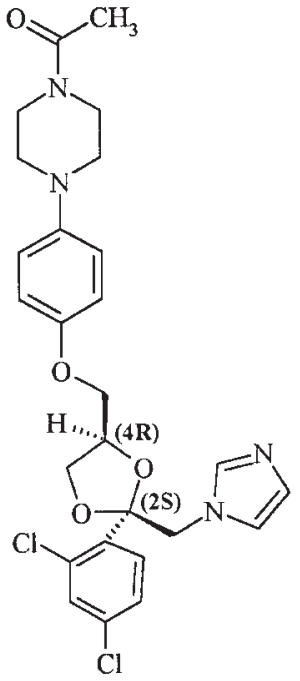

$(-)-(2 S, 4 R)$
Figure 1. The structures of the enantiomers of ketoconazole.

configuration for these molecules means that the hydrogen and the 2,4-dichlorophenyl group at the two stereogenic (chiral) centers, respectively, are on the same side of the five-membered (dioxolane) ring. It is important to note that this cis configuration is present in both enantiomers of KETO (Fig. 1). The absolute configuration of the enantiomers has been determined [6] to be (+)-2R,4S and (-)$2 S, 4 R$ (Fig. 1), the 2-position being the center with the dichlorophenyl substituent, and the 4-position the other chiral center. Thus, the $2 R, 4 S$ - enantiomer is dextrorotatory and the $2 S, 4 R$ - enantiomer is levorotatory.

The stereochemistry of ITRA is more complex, due to the presence of a third chiral center, in the sec-butyl moiety in the side chain (Fig. 2). The drug is in fact a mixture of the two racemates, i.e. four stereoisomers, shown in figure 2. In all four stereoisomers the hydrogen and the dichlorophenyl substituents at the two chiral centers of the dioxolane ring 


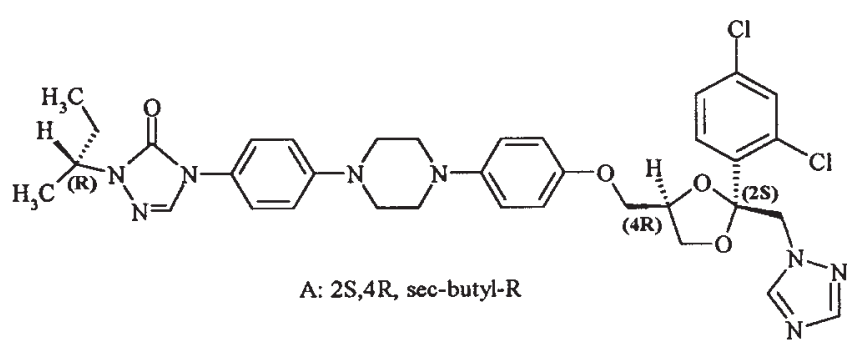

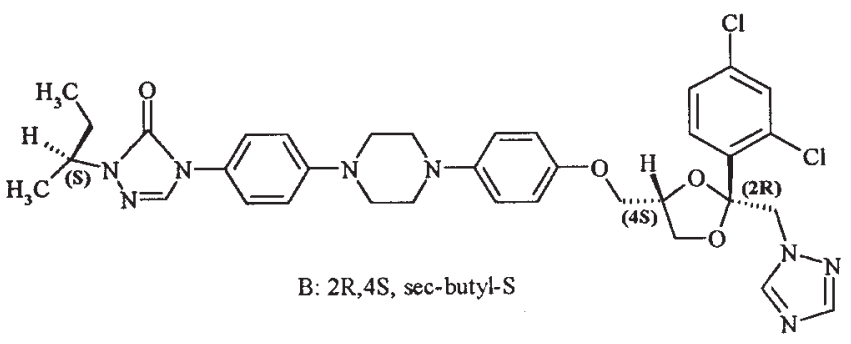

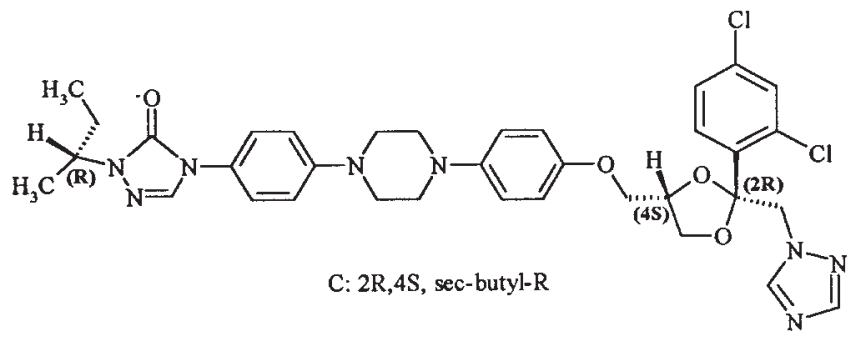<smiles>CC[C@@H](C)n1ncn(-c2ccc(N3CCN(c4ccc(OC[C@@H]5CO[C@@](Cn6cncn6)(c6ccc(Cl)cc6Cl)O5)cc4)CC3)cc2)c1=O</smiles>

Figure 2. The structures of the four stereoisomers of itraconazole.

(i.e., the same as in KETO) are in the cis arrangement. Molecules A and B in figure 2 are the two enantiomers of one of the two racemates in ITRA, and molecules $\mathrm{C}$ and $\mathrm{D}$ are the enantiomers of the other racemate. Any molecule from either racemate (e.g., A) is related to either of the molecules from the other racemate (e.g., C) as diastereoisomers, i.e., as stereoisomers that are not enantiomers (non-superposable mirror-image forms) of each other. Furthermore, the diastereoisomerically-related $\mathrm{A}$ and $\mathrm{D}$ are also epimers of each other, i.e., differ in the configuration of only one (the sec-butyl center) of the three chiral centers. The same epimeric relationship is true for $\mathrm{B}$ and $\mathrm{C}$. The absolute configurations (i.e., the optical rotation of each of A-D) do not appear to have been published.

Stereochemistry is an important modulator of biological effects of drugs [7], and it is of interest therefore to examine the potential stereoselectivity in the pharmacodynamic and pharmacokinetic properties of KETO and ITRA, to determine whether the clinical use of an individual stereoisomer may have advantages over the stereoisomeric mixture. Prerequisite for such studies, however, are methods for the chromatographic separation of the stereoisomers, for both analytical and preparative purposes. In this report we describe our findings on the chromatographic separation of the stereoisomers of KETO and ITRA.

\section{Experimental}

ChiralCel OD and ChiralPak AS were from Chiral Technologies (Exton, PA, USA). The chemical pathway for the synthesis of the regioselectively derivatized polysaccharides was described previously [8,9]. They consist of two regioselectively derivatized polysaccharides: the 6-(Rphenylethylcarbamate)-2,3-(3,5-dimethylphenyl carbamate) cellulose (CSP-1) derivative, and the 6-(R-phenylethylcarbamate)-2,3-(3,5-dimethylphenyl carbamate) amylose (CSP2) derivative, respectively. The chiral packing materials were prepared as reported elsewhere [10]. Each chiral material was packed in stainless-steel tubes $(250 \times 4.6 \mathrm{~mm} \mathrm{ID})$ by the slurry method. The structures of the chiral stationary phases (CSPs) are presented in figure 3.

Chromatographic separations were carried out with an HPLC system including a Jasco UV-975 UV/VIS detector and a Jasco PU-980 HPLC pump. The SFC separations were performed on a Gilson SF3 system equipped with a Rainin Dynamax model UV/VIS detector. Optical-rotation detection

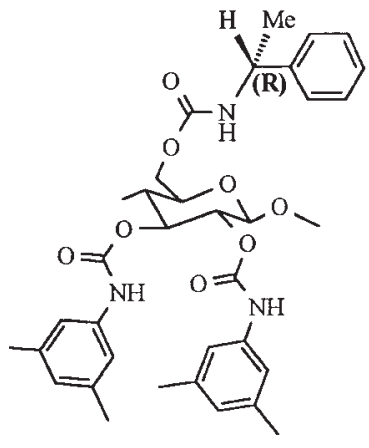

CSP-1

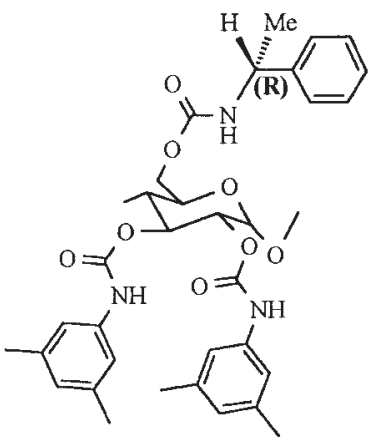

CSP-2

Figure 3. The structures of the chiral stationary phases. 
during liquid chromatographic analyses was carried out with a JASCO OR 990 chiral detector.

The drugs were dissolved in ethanol at a concentration of $1 \%$ and $3 \%$ for analysis by HPLC and SFC respectively. Racemic KETO was obtained from Betachem Inc. (Franklin Lakes, NJ, USA). The two enantiomers of ketoconazole were kindly provided by Dr. D. M. Rotstein, Syntex Research (Palo Alto, CA, USA). ITRA (mixture of four stereoisomers) was extracted from Sporanox brand 100-mg capsules of itraconazole as follows: the contents of five capsules were mixed with $20 \mathrm{ml}$ of $5 \%(\mathrm{w} / \mathrm{v})$ sodium hydrogen carbonate solution, and the mixture was extracted twice with $30-\mathrm{ml}$ aliquots of dichloromethane. The organic extracts were combined, the organic solution was filtered through glass wool and was dried over anhydrous potassium carbonate, followed by evaporation of the solvent at reduced pressure. The residual oil was induced to crystallize by scratching the container wall with a glass rod. A colorless solid $(393 \mathrm{mg})$ was obtained, MP $164{ }^{\circ} \mathrm{C}\left(166.2{ }^{\circ} \mathrm{C}\right.$ in litt. [11]).

\section{Results and discussion}

\section{Studies in HPLC}

In preliminary studies [12], it was found that the enantiomers of KETO could be separated by HPLC on ChiralPak AD. The chromatography of ITRA on ChiralCel OD, however, gave only two peaks for the four stereoisomers (data not shown). It was tentatively concluded that each peak corresponded to an epimeric mixture from the drug. That is, that each of these two mixtures consisted of two stereoisomers differing only in the configuration at the sec-butyl stereogenic center, i.e., the mixtures $\mathrm{A}+\mathrm{D}$ and $\mathrm{B}+\mathrm{C}$ (figure 2), respectively. The alternative interpretation, i.e., that the two peaks corresponded to the two racemates, i.e., $\mathrm{A}+\mathrm{B}$ and $\mathrm{C}+\mathrm{D}$, respectively, was not supported by the observation that the first peak was due to dextrorotatory material, while the second peak was levorotatory, since no net rotation would be observed for a racemate.

These promising results prompted us to use, as CSPs, polysaccharides substituted with various groups at positions 2,3 and 6 of the glucose moiety of the polysaccharide. Previous work $[8,9]$ has shown that these CSPs display excellent chiral discrimination when compared to Chiralcel OD and ChiralPak AD. The results obtained in the present study for KETO and ITRA are collected in table I, showing the retention factors k. For KETO, the resolution factor Rs was 1.7 with an enantioselectivity factor $\alpha$ of 1.5 on CSP1 ; while on CSP-2, Rs was 1.53 with $\alpha$ of 1.17 . Thus, CSP2 is somewhat less enantioselective than CSP-1. For ITRA, four peaks were obtained, with the following separation parameters (Tab. II): as shown by the chromatogram in figure 4 and the data in table II, only the separation of peaks 2 and 3 was poor. Since the individual stereoisomers of
Table I. HPLC separation of ketoconazoles and itraconazoles.

\begin{tabular}{lcccccc} 
Compound CSP & $k_{1}$ & $k_{2}$ & $k_{3}$ & $k_{4} \begin{array}{c}\text { Mobile } \\
\text { phase }\end{array}$ \\
\hline Ketoconazole CSP-1 & $10.8(+)$ & $15.6(-)$ & & & $\mathrm{A}$ \\
Ketoconazole CSP-2 & $14.2(+)$ & $17.2(-)$ & & & $\mathrm{B}$ \\
Itraconazole CSP-2 & $24.3(+)$ & $28.3(-)$ & $30(+)$ & $33(-)$ & $\mathrm{C}$ \\
\hline
\end{tabular}

Mobile phases:

A) hexane-isopropanol, 70-30 (v/v), plus octanoic acid (10 mmol). B) hexane-methanol-ethanol, 80-05-15 (v/v/v), plus octanoic acid (10 mmol).

C) hexane-methanol-ethanol, 75-12-13 (v/v/v), plus octanoic acid (10 mmol).

Flow rate: $1 \mathrm{ml} / \mathrm{min}$. Detection: UV, $254 \mathrm{~nm}$.

Table II. HPLC separation parameters for the resolution of ITRA on CSP-2.

\begin{tabular}{lccc}
\hline & \multicolumn{3}{c}{ Separation between peaks ${ }^{*}$} \\
\hline Parameter & 1,2 & 2,3 & 3,4 \\
$\alpha$ & 1.16 & 1.05 & 1.10 \\
Rs & 1.94 & 0.68 & 1.13 \\
\hline
\end{tabular}

* Parameters 1,$2 ; 2,3$ and 3,4 refer to the elution order of the four peaks ( 1 for the least-retained isomer).

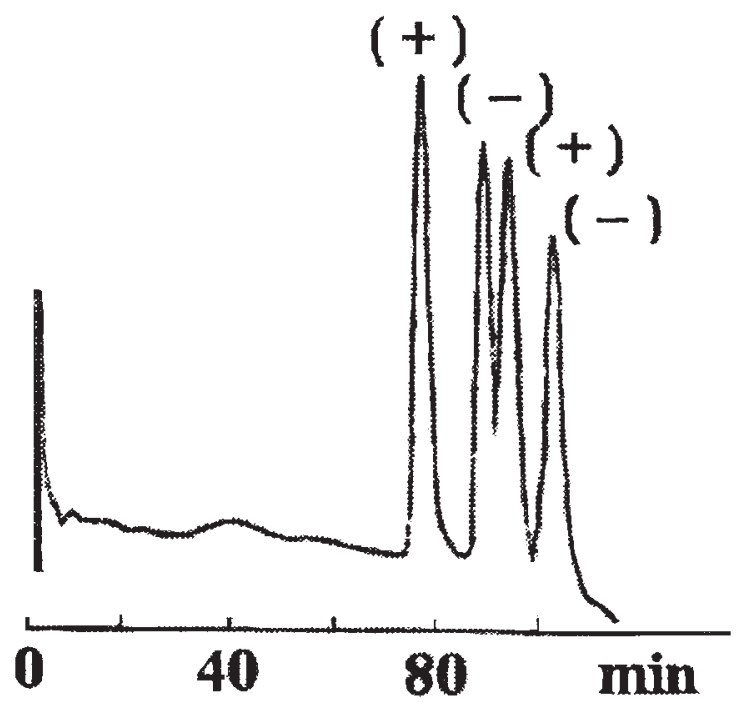

Figure 4. HPLC separation of itraconazole isomers on CSP-2. Chromatographic conditions: as in table I with mobile phase $\mathrm{C}$. 
ITRA were not available and their absolute configuration does not appear to have been published, the peaks in figure 4 could not be assigned to the stereoisomers shown in figure 2 for ITRA.

\section{Studies in SFC}

These studies, carried out using CSP-2, examined the influence of pressure as well as the nature and percentage of the polar modifier.

\section{Resolution of KETO}

\section{Influence of pressure}

The results are presented in table III. Varying the pressure does not significantly affect the enantioselectivity. Increasing the pressure (and the corresponding reduction in retention) only modestly reduced the separation factor $R_{s}$. It is therefore worth increasing the pressure to a level still producing adequate resolution while reducing the retention time. Thus, the remainder of this study on KETO was carried out at $35 \mathrm{MPa}$.

\section{Influence of the nature and percentage of the polar modifier}

The results are shown in table IV. Increasing the proportion of the modifier in the mobile phase causes only a slight decrease in enantioselectivity and a modest decrease in the separation factor. It may be useful therefore to increase the percentage of the polar modifier to a degree that, while shortening the retention time, does not adversely affect the resolution. It was also found that varying the methanol/ethanol proportion in the polar modifier causes only negligible changes in retention time, enantioselectivity, and resolution.

\section{Resolution of ITRA}

Four peaks were obtained and, as in the HPLC separations, only peaks 2 and 3 were poorly resolved. Therefore, in the following tables only $\alpha_{2,3}$ and $\mathrm{Rs}_{2,3}$ will be presented.

\section{Influence of pressure}

If the goal is to improve the separation at the expense of longer retention times, it is possible to reduce the pressure, as seen in table V. As for KETO above, pressure has only a negligible influence on enantioselectivity and a modest effect on the separation factor, but a strong influence on retention.

\section{Influence of the percentage of the polar modifier}

Under conditions of optimal pressure (35 MPa), varying the percentage of polar modifier has the following effects (Tab. VI): increasing the percentage of the polar modifier causes a significant reduction in run time, varying the percentage of polar modifier however has a negligible effect on enantioselectivity and resolution. Thus, to achieve an
Table III. SFC separation of ketoconazole on CSP-2.

\begin{tabular}{lccc}
\hline Column outlet pressure & $25 \mathrm{MPa}$ & $30 \mathrm{MPa}$ & $35 \mathrm{MPa}$ \\
\hline $\mathrm{k}_{1}$ & $9.12(+)$ & $7.51(+)$ & $6.37(+)$ \\
$\mathrm{k}_{2}$ & $11.90(-)$ & $9.67(-)$ & $8.21(-)$ \\
$\alpha$ & 1.30 & 1.29 & 1.29 \\
$\mathrm{Rs}$ & 0.80 & 0.72 & 0.73 \\
\hline
\end{tabular}

Mobile Phase: $\mathrm{CO}_{2}$ with $20 \%$ modifier. Modifier: methanol-ethanol, 1/3-2/3, plus octanoic acid (10 mmol). Column outlet pressure: variable $(25,30$ and $35 \mathrm{MPa})$. Column temperature: $30{ }^{\circ} \mathrm{C}$. Flow rate: $2.5 \mathrm{ml} / \mathrm{min}$. Detection: UV, $254 \mathrm{~nm}$.

Table IV. SFC separation of ketoconazole on CSP-2.

\begin{tabular}{lccc}
\hline$\%$ of modifier & $17 \%$ & $20 \%$ & $25 \%$ \\
\hline $\mathrm{k}_{1}$ & $9.3(+)$ & $6.4(+)$ & $3.7(+)$ \\
$\mathrm{k}_{2}$ & $12.2(-)$ & $6.6(-)$ & $4.7(-)$ \\
$\alpha$ & 1.30 & 1.29 & 1.27 \\
$\mathrm{Rs}$ & 0.83 & 0.73 & 0.75 \\
\hline
\end{tabular}

Mobile Phase: $\mathrm{CO}_{2}$ with different pourcentages of modifier (17, 20 and $25 \%)$. Modifier: methanol-ethanol, 1/3-2/3, plus octanoic acid (10 mmol). Column outlet pressure: $35 \mathrm{MPa}$. Column temperature: $30{ }^{\circ} \mathrm{C}$. Flow rate: $2.5 \mathrm{ml} / \mathrm{min}$. Detection: UV, $254 \mathrm{~nm}$.

Table V. SFC separation of itraconazole on CSP-2.

\begin{tabular}{lcc}
\hline Column outlet pressure & $35 \mathrm{MPa}$ & $30 \mathrm{MPa}$ \\
\hline $\mathrm{k}_{1}$ & 24.0 & 28.8 \\
$\mathrm{k}_{4}$ & 34.3 & 41.3 \\
$\alpha_{2,3}$ & 1.07 & 1.07 \\
$\mathrm{Rs}_{2,3}$ & 0.64 & 0.60 \\
\hline
\end{tabular}

Mobile Phase: $\mathrm{CO}_{2}$ with $20 \%$ modifier. Modifier: methanol-ethanol, 1/3-2/3, plus octanoic acid (10 mmol). Column outlet pressure: variable (35 and $30 \mathrm{MPa}$ ). Column temperature: $30{ }^{\circ} \mathrm{C}$. Flow rate: $2.5 \mathrm{ml} / \mathrm{min}$. Detection: UV, $254 \mathrm{~nm}$.

Table VI. SFC separation of itraconazole on CSP-2.

\begin{tabular}{lll}
\hline$\%$ of modifier & $20 \%$ & $17 \%$ \\
\hline $\mathrm{k}_{1}$ & 24.0 & 35.7 \\
$\mathrm{k}_{4}$ & 34.4 & 51.6 \\
$\alpha_{2,3}$ & 1.07 & 1.07 \\
$\mathrm{Rs}_{2,3}$ & 0.64 & 0.74 \\
\hline
\end{tabular}

Mobile phase: $\mathrm{CO}_{2}$ with different percentages of modifier (20 and $17 \%)$. Modifier: methanol-ethanol, 1/3-2/3, plus octanoic acid (10 mmol). Column outlet pressure: $35 \mathrm{MPa}$. Column temperature: $30{ }^{\circ} \mathrm{C}$. Flow rate: $2.5 \mathrm{ml} / \mathrm{min}$. Detection: UV, $254 \mathrm{~nm}$. 


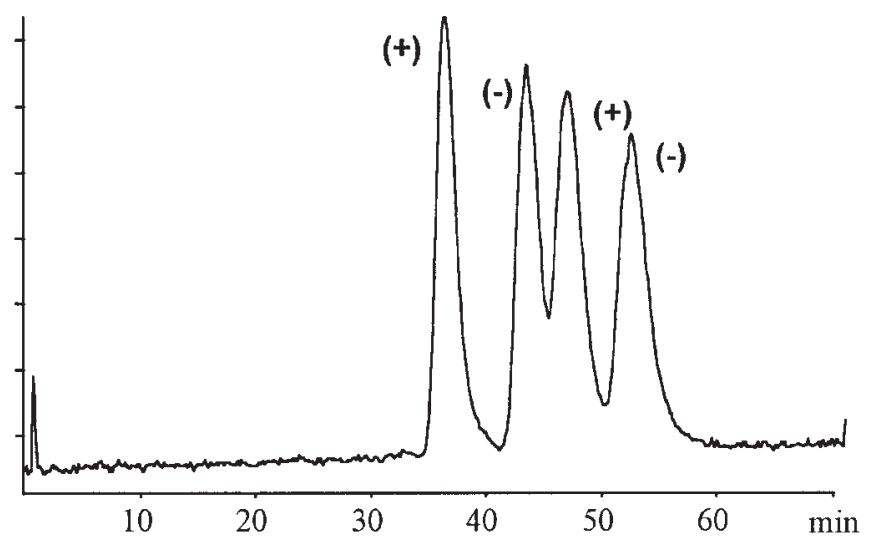

Figure 5. SFC separation of itraconazole isomers on CSP-2. Mobile phase: $\mathrm{CO}_{2}$ with $17 \%$ modifier. Modifier: methanol-ethanol, $1 / 3-2 / 3$, plus octanoic acid $(10 \mathrm{mmol})$. Column outlet pressure: $35 \mathrm{MPa}$. Column temperature: $30^{\circ} \mathrm{C}$. Flow rate: $2.5 \mathrm{ml} / \mathrm{min}$. Detection: UV, $254 \mathrm{~nm}$.

improvement in the separation at the expense of longer retention time, the percentage of polar modifier should be reduced. For CSP-2, figure 5 shows the separation achieved and the order of elution of the stereoisomers. It is interesting to observe that the dextrorotatory epimers of the epimeric mixture that elutes first as one peak on the Chiralcel OD CSP are eluted as two peaks (1 and 3) on CSP2 , and the other epimeric set also as two peaks ( 2 and 4$)$. Thus, the two epimers in each epimeric mixture are separable under these conditions.
Influence of the proportion of methanol in the modifier

A study of the influence of the proportion of methanol and ethanol in the polar modifier was also carried out, and the results are presented in tables VII and VIII. It is thus clear for itraconazole that the greater the proportion of methanol in the modifier, the longer the retention times become. One would however expect to observe the opposite of these results, because methanol is more polar than ethanol. This apparent discrepancy is explained by the reduction in the solubility of the drug as the proportion of ethanol is decreased, thereby increasing the retention times. Therefore, the organic modifier must contain a sufficient quantity of ethanol to reduce the retention time while maintaining the quality of the separations.

\section{Conclusions}

The use of SFC has allowed the development of shorter analyses while still maintaining the separations of KETO and ITRA obtained by HPLC on CSP-2. Furthermore, increasing the pressure allows even shorter run times without adversely affecting the separations. Similarly, varying the percentage of the polar modifier suitably can further reduce the retention times. However, it would be prudent to keep these changes within certain limits, since exceeding them would cause a departure from subcritical conditions with respect to pressure and would also damage the column. We believe that the separation methods developed will contribute to studies of KETO and ITRA aimed at developing safer forms of these antifungal agents on the basis of stereochemical considerations.

Table VII. SFC separation of itraconazole on CSP-2.

\begin{tabular}{lccccc}
\hline \multicolumn{2}{l}{$\begin{array}{l}\text { Column outlet pressure } \\
\text { MeOH-EtOH }(v / v)\end{array}$} \\
$\begin{array}{l}\text { plus octanoic acid } \\
(10 \mathrm{mmol})\end{array}$ & $1 / 3-2 / 3$ & $1 / 2-1 / 2$ & $1 / 3-2 / 3$ & $1 / 2-1 / 2$ & $2 / 3-1 / 3$ \\
\hline $\mathrm{k}_{1}$ & & & & \\
$\mathrm{k}_{2}$ & 37.0 & 50.1 & 29.8 & 31.2 & 34.0 \\
$\mathrm{k}_{3}$ & 44.3 & 58.4 & 35.5 & 37.4 & 41.5 \\
$\mathrm{k}_{4}$ & 47.6 & 63.5 & 38.0 & 40.5 & 45.5 \\
$(\alpha / \mathrm{Rs})_{1,2}$ & 53.4 & 73.2 & 43.1 & 45.4 & 51.0 \\
$(\alpha / \mathrm{Rs})_{2,3}$ & $1.2 / 1.6$ & $1.16 / 1.78$ & $1.19 / 1.7$ & $1.19 / 2.0$ & $1.22 / 1.69$ \\
$(\alpha / \mathrm{Rs})_{3,4}$ & $1.07 / 0.6$ & $1.09 / 1.01$ & $1.07 / 0.64$ & $1.08 / 0.86$ & $1.09 / 0.79$ \\
\hline
\end{tabular}

Mobile Phase: $\mathrm{CO}_{2}$ with $20 \%$ modifier. Modifier: variable. Column outlet pressure: variable (30 and $\left.35 \mathrm{MPa}\right)$. Column temperature: $30{ }^{\circ} \mathrm{C}$. Flow rate: $2.5 \mathrm{ml} / \mathrm{min}$. Detection: UV, $254 \mathrm{~nm}$. 
Table VIII. SFC separation of itraconazole on CSP-2.

\begin{tabular}{lccc}
\hline \multicolumn{3}{l}{ Column outlet pressure } & $35 \mathrm{MPa}$ \\
\hline $\begin{array}{l}\text { MeOH-EtOH }(\mathrm{V} / \mathrm{V}) \\
\text { plus octanoic acid } \\
(10 \mathrm{mmol})\end{array}$ & $1 / 3-2 / 3$ & $1 / 2-1 / 2$ & $2 / 3-1 / 3$ \\
\hline $\mathrm{k}_{1}$ & & & \\
$\mathrm{k}_{2}$ & 44.8 & 46.9 & 49.1 \\
$\mathrm{k}_{3}$ & 54.1 & 65.6 & 58.2 \\
$\mathrm{k}_{4}$ & 58.2 & 62.8 & 63.6 \\
$(\alpha / \mathrm{Rs})_{1,2}$ & 65.1 & 69.8 & 70.2 \\
$(\alpha / \mathrm{Rs})_{2,3}$ & $1.20 / 2.04$ & $1.20 / 2.0$ & $1.18 / 1.84$ \\
$(\alpha / \mathrm{Rs})_{3,4}$ & $1.07 / 0.74$ & $1.10 / 1.11$ & $1.09 / 0.98$ \\
\hline
\end{tabular}

Mobile Phase: $\mathrm{CO}_{2}$ with $17 \%$ modifier. Modifier: variable. Column outlet pressure: $35 \mathrm{MPa}$. Column temperature: $30{ }^{\circ} \mathrm{C}$. Flow rate: $2.5 \mathrm{ml} / \mathrm{min}$. Detection: UV, $254 \mathrm{~nm}$.

\section{References}

1. Beck-Sague, C. M.; Jarvis, W. R. J. Infect. Dis. 1993, 167, 1247-1251.

2. Fisher-Hoch, S. P.; Hutwagner, L. Clin. Infect. Dis. 1995, 21, 897-904.

3. Como, J. A.; Dismukes, W. E. New Engl. J. Med. 1994, 330, 263-272.

4. Michalets, E. L. Pharmacotherapy 1998, 18, 84-112.

5. Pohjola-Sintonen, S.; Viitasalo, M.; Toivonen, L.; Neuvonen, P. Eur. J. Clin. Pharmacol. 1993, 45, 191-193.

6. Rotstein, D. M.; Kertesz, D. J.; Walker, K. A.; Sweeney, D. C. J. Med. Chem. 1992, 35, 2818-2825.

7. Eichelbaum, M.; Gross, A. S. Adv. Drug Res. 1996, 28, 2-64.

8. Chassaing, C.; Thienpont, A.; Félix, G. J. Chromatogr. 1996, 738, 157-167.

9. Chassaing, C.; Thienpont, A.; Soulard, M.-H.; Félix, G. J. Chromatogr. 1997, 786, 13-21.

10. Okamoto, Y.; Honda, S.; Okamoto, I.; Huki, H.; Murata, S.; Nayori, R.; Takaya, H. J. Amer. Chem. Soc. 1981, 103, 69716973.

11. Heeres, J.; Backx, L. J. J.; Van Cutsem, J. J. Med. Chem. 1984, 27, 894-900.

12. Gal, J.; Aeschlimann, C.; Félix, G., Fourth International Symposium on Chiral Discrimination, Montreal, Canada, September 19-22, 1993, Abstract 130. 